\title{
Supporting Organisational Learning through the Enrichment of Documents
}

\author{
Dr. John Domingue \\ Deputy Director \\ The Knowledge Media Institute \\ The Open University \\ Milton Keynes, England \\ j.b.dominguedopen.ac.uk \\ kmi.open.ac.uk/people/domingue
}

Studies show that only $10 \%$ of corporate training is ever applied within the workplace. This is because organisations tend to use school based methods of learning which are not appropriate. Our approach, based on theories of learning in the workplace, supports organisational learning and knowledge sharing by enriching web documents with informal and formal representations. This enrichment captures the context in which a document was created and has been applied, facilitating its retrieval and comprehension. 